\title{
la experiencialidad como respuesta a la tendencia analítica de la filosofía para niños ${ }^{1}$
}

\author{
josé barrientos-rastrojo ${ }^{2}$ \\ universidad de sevilla, españa
}

\section{resumen}

Las sesiones de Filosofía para Niños se han fundado en muchos autores (como Oscar Brenifier) en patrones analíticos y conceptuales. Aun cuando han estudiado elementos afectivos y emocionales, las metodologías desarrolladas en el aula responden a este formato, es decir, la principales herramientas de trabajo acostumbran a ser la argumentación, la creación de definiciones, el diseño de descripciones, el análisis conceptual, la confrontación de tesis o la construcción de nuevas teorías o estructuras ideacionales, entre otras. Esto es debido al tipo de racionalidad sobre la que descansan muchas teorías de Filosofía para Niños: una filosofía entendida como proceso argumentivo que establece y critica hipótesis y estructura analíticamente la realidad. Sin embargo, el siglo XX y XXI ha traído otras formas de filosofía: la razón vital y narrativa de Ortega y Gasset, la razón poética de María Zambrano, la razón dramática de Sartre, los sones místicos de Heidegger y la razón ontológico-estética de Gadamer o de Benjamin, por poner sólo algunos ejemplos. Algunos autores han realizado aproximaciones estéticas en Filosofía para Niños, por ejemplo, las reflexiones artísticas de Kohan y Vaksman han trabajado con objetos de arte y Sátiro ha materializado traducciones desde lo plástico a lo oral y viceversa. No obstante, es urgente reflexionar sobre una modalidad de Filosofía para Niños cuyo foco de interés no sea exclusivamente la reflexión sobre nuevo material sino el trabajo con material nuevo. De esta forma, se crearía un pensamiento más allá de los modos analíticos tradicionales: comprender no consistiría sólo en una acción crítica sino en una forma de pensar sin palabras. El presente trabajo propone una aproximación a la Filosofía para Niños desde una de esas racionalidades: la experiencia de la vida o experiencialidad.

palabras clave: experiencialidad; filosofía para niños; experiencia; filosofía analítica.

\section{a experiencialidade como resposta à tendência analítica da filosofia para crianças}

resumo

As sessões de Filosofia para Crianças foram fundadas em muitos autores (como Oscar Brenifier) nos padrões analíticos e conceituais. Ainda quando são estudados elementos afetivos e emocionais, as metodologias desenvolvidas na sala de aula respondem a este formato, ou seja, as principais ferramentas de trabalho costumam ser a argumentação, a criação de definições e de descrições, a análise conceitual, a confrontação da tese ou a construção de novas teorias ou estruturas ideacionais, entre outras. Isso devido ao tipo de racionalidade sobre a qual descansam muitas teorias de Filosofia para Crianças: uma filosofia entendida como processo argumentativo, que estabelece e critica hipóteses e

\footnotetext{
${ }^{1}$ Este artículo se ha desarrollado en el seno del proyecto de investigación "Ciencia, Tecnología y Sociedad: Problemas políticos y éticos de la computación en nube como nuevo paradigma socioético" (Referencia: FFI2013-46908-R)" al que pertenece el autor y del grupo de investigación "Experiencialidad" (Referencia: HUM 964).

2 E-mail: barrientos@us.es
} 
estrutura analiticamente a realidade. No entanto, os séculos XX e XXI trouxeram outras formas de filosofia: a razão vital e narrativa de Ortega y Gasset, a razão poética de Maria Zambrano, a razão dramática de Sartre, os sons místicos de Heidegger e a razão ontológico-estética de Gadamer ou de Bejnamin, para citar apenas alguns exemplos. Alguns autores fizeram aproximações estéticas na Filosofia para Crianças, por exemplo, as reflexões artísticas de Kohan e Vaksman, que têm trabalhado com objetos de arte e Sátiro, que materializou traduções do plástico para o oral e vice-versa. Não obstante, é urgente refletir sobre uma modalidade de Filosofia para Crianças cujo foco de interesse não seja exclusivamente a reflexão sobre material novo senão o trabalho com material novo. Dessa forma, se criaria um pensamento para além dos modos analíticos tradicionais: compreender não consistiria somente em uma ação crítica, mas em uma forma de pensar sem palavras. O presente trabalho propõe uma aproximação à Filosofia para Crianças desde uma dessas racionalidades: a experiência da vida ou a experiencialidade.

palavras-chave: experiencialidade; filosofia para crianças; experiência; filosofia analítica.

\section{the experientiality as a response to the analytical tendency of philosophy for children}

abstract

Sessions of Philosophy for Children has been based in many authors (as Oscar Brenifier) in analytical and conceptual patterns. Even when they have been devoted to study affective and emotional topics, methodologies implemented in the classroom are grounded in those patterns; so that, its main tools are the use of arguments, the creation of definitions, the design of descriptions, the conceptual analysis, the confrontation of thesis and the building of new theories or ideational structures, among others. This is due to the type of rationality on which rests a lot of theories of Philosophy for Children: a philosophy understood as argumentative process that establishes and critic thesis and that structures analytically the reality. In spite of this approach, $20^{\text {th }}$ and $21^{\text {st }}$ century have brought other forms of philosophy: the Ortega y Gasset's vital and narrative reason, the María Zambrano's poetic reason, the sartrian dramatic reason, the mystical sounds founded at the works by of Heidegger and the Gadamerian and Benjaminian ontologicalaesthetic reason, among others. Some authors have proposed aesthetic approaches in philosophy for children, for example Kohan and Waksman have work with artistic objects in sessions and Sátiro has worked by through of translating plastic to oral language and the opposite. However, it is urgent to reflect on a form of philosophy for children whose focus is not exclusively reflection on new materials but to perform with new material. It would create a thought beyond the traditional analytical ways: understanding will be not just a critical action but a way of thinking without words. This paper proposes an approach to Philosophy for Children from one of those rationalities: life experience or experienciality.

keywords: experienciality; philosophy for children; experience; analytic philosophy. 
la experiencialidad como respuesta a la tendencia analítica de la filosofía para niños

\section{1. introducción: analiticos en la filosofía para niños.}

Franca D'Agostini trajo a palestra pública en 1997 una escisión, que se puede rastrear al menos desde la diferencia entre las naturwissenchaften y las geistewissenchaften y que ha transitado la última parte de la contemporaneidad: la analítica y la continental (D'AGOSTINI, 2000). La teoría ha sido continuada por Luis Sáez Rueda (SÁEZ RUEDA, 2002), entre otros, y, también, cuestionada por algunos pensadores ${ }^{3}$. Sea como fuere, constituye un modelo de organización de la filosofía contemporánea útil para localizar corrientes, escuelas y filósofos.

Los analíticos heredan tradiciones como el positivismo, el empirismo lógico, el pragmatismo y el kantismo; los continentales se hacen acreedores de la fenomenología, las tendencias metafísicas y ontológicas y el hegelianismo (D'AGOSTINI, 2000, pp-79-105). Los primeros integran desde Frege a Kripke pasando por Wittgenstein o Russell y el segundo desde Heidegger a Deleuze o Foucault pasando por Gadamer o Habermas.

Durante gran parte del siglo $X X$, la filosofía analítica se autoerigió como canon de validez en las universidades anglófonas ${ }^{4}$ puesto que fomentaba una idea común de filosofía; mientras, la continental rompía este marco y facilitaba modos plurales de entender la filosofía desde una razón hermenéutica a una poética, pasando por una simbólica, una dramática, una estética o una mística.

La situación actual es doble. Por una parte, se dibujan convivencias entre los dos marcos: Wittgenstein posee una primera etapa analítica y una segunda más conectada con los intereses continentales, Strawson (2012), y sin abandonar la filosofía analítica, critica a Russell y se acerca a una lógica de naturaleza trascendental en Introduction to logical Theory y La transformación de la filosofía de Appel (APPEL, 1985a; 1985b), El conflicto entre continentales y analíticos escrito por Sáez Rueda (SÁEZ RUEDA, 2002) o la filosofía de Tugendhat (D'AGOSTINI, 2000, p. 94) establecen conexiones fuertes entre ambas orientaciones. De hecho, temas

\footnotetext{
${ }^{3}$ Autores tradicionalmente analíticos han transitado en los últimos años hacia la continentalidad y viceversa, aunque se suelen mantener las tendencias. Casos conocidos podría ser el del recientemente fallecido Hillary Putnam, con su defensa (en ocasiones) y crítica (en otras) del realismo metafísico, a crítica de Rorty a la insuficiencia del pragmatismo de corte analítico (D'AGOSTINI, 2000, p. 94), incluso autores como Tugendhat, alumno de Heidegger, acabó en la Filosofía Analítica (pueden analizarse estos casos y otros en las páginas 94 y siguientes de la citada obra de D'Agostini). Por otro lado, ha habido intentos de síntesis o entendimientos entre las dos formas de aproximación filosófica: Mauricio Beuchot desde una postura analítica y positivista en los años setenta y principios de los ochenta buscará afiliarse a una más continental en los noventa desde el punto intermedio de su hermenéutica analógica (la cual persigue equilibrar el univocismo cientificista -analítico- con el equivocismo romántico - continental), análogo es el caso previo de la razón poética de Zambrano que busca salvar los dos extremos.

${ }^{4}$ Aun hoy, muchas de las mejores revistas internacionales y facultades de la disciplina están determinadas por esta corriente. Ése es el caso de las Facultades de Filosofía de Cambridge, Oxford o Harvard o las revistas Crítica de la Universidad Nacional Autónoma de México o Teorema de la Universidad de Oviedo.
} 
que, se considera, enraízan el pensamiento analítico son también fundamento de la filosofía continental; tal es el caso del lenguaje.

Por otro lado, las diferencias y oposiciones no son ajenas tampoco a la contemporaneidad. La filosofía analítica se caracteriza por el interés por la lógica, las ciencias naturales exactas y sobre lo descriptivo (D'AGOSTINI 2000, p.24); la filosofía continental posee un sesgo más metafísico, ontológico y se conecta con una hermenéutica que antepone la comprensión ontológica a la metodología técnica ${ }^{5}$. La primera sería heredera de la "explicación", del ideal de la filosofía como ciencia pura y de las ciencias de la naturaleza y la segunda tributaría a la comprensión, de una filosofía que ahonda en las raíces metafísicas de lo real y de las ciencias del espíritu. Así, los analítico-pragmáticos censuran lo abstruso y oscuro de las teorías continentales (JAMES, 2000, pp- 78-101) o sus argumentaciones "hiperbólicas" y "facciosas" (D'AGOSTINI, 2000, p.90). Los continentales se centrará en la "superficialidad" y el tecnicismo "huero" de los otros (ADORNO citado en D'AGOSTINI, 2000, p. 24).

El germen de la Filosofía para Niños se encuentra en un filósofo estadounidense que fue alumno del pragmatista John Dewey: Matthew Lipman. Si seguimos, arqueológicamente, este sendero, descubrimos que Dewey tuvo relación con la primera hornada de analíticos que viajan a Estados Unidos huyendo de las hordas nazis; de hecho, participó en uno de sus proyectos más ambiciosos liderado por Carnap, Neurath y Morris: la International Encyclopedia of Unified Science (D'AGOSTINI, 2000, p. 265).

Actualmente, la obra de la Filosofía para Niños no sólo abarca referencias bibliográficas a Dewey, sino que añade a Wittgenstein y a pragmatistas como Putnam, Peirce o Ryle, entre otros. Esto es coherente con la atención que sus metodologías sostienen sobre el lenguaje y el razonamiento lógico ${ }^{6}$. El panorama es muy diferente si indagamos en las fuentes continentales de los escritos de Lipman, Echeverría, Sátiro o Carreras7. Únase a esto cómo Lipman se enraíza en los presupuestos pragmáticos que vinculan racionalidad y democracia ${ }^{8}$.

Sea como fuere, el fundador oficial de la Filosofía para Niños comienza su labor en uno de los países donde la preponderancia de la filosofía analítica es indiscutida y en el que las líneas continentales tienen tendencia a ser exiliadas de las facultades de filosofía y a encontrar cobijo en otros departamentos como los de literatura, filología e incluso arte.

Nuestra tesis asevera que esta orientación se ha infiltrado en la mayor parte de los teóricos de esta profesión. Así, Oscar Brenifier o la española Carla

\footnotetext{
${ }^{5}$ Muestra de ello es el acceso a la alteridad en el personalista Levinas (1993) o la aproximación ontológica a la hermenéutica de Gadamer (1993), que le criticará desde una visión más técnica E. Betti por su falta de técnica.

${ }^{6}$ El primer libro lipmaniano de Filosofía para Niños, El descubrimiento de Harry (LIPMAN, 1997), se centra en el estudio y aplicación de la lógica.

7 Como muestra un botón: la bibliografía de la página web del primer centro de Filosofía para Niños en España destaca esta importancia de las obras analíticas y el olvido de las de autores continentales (véase http:/ /www.filosofiaparaninos.org/Bibliografia/bibliografia_fpn.htm, último acceso 20 de diciembre de 2013).

${ }^{8}$ Esta idea jalona, por ejemplo, Cómo pensamos de John Dewey (2007).
} 
Carreras, cuya tesis doctoral se tituló La herencia deweyana: la "Philosophy for Children" de Matthew Lipman y las bases del conocimiento, subrayan las competencia analíticas y lingüísticas como eje de la labor del filósofo en esta área de conocimiento.

A la luz de la doble vertiente de las corrientes actuales de la filosofía citada, sería oportuno incentivar los abordajes continentales de la Filosofía para Niños por dos razones: (1) hacer justicia a la implementación práctica de los marcos contemporáneos de forma integral, que aparecen menos representados en este área de conocimiento, aunque existan algunos y (2) incentivar la apertura, iniciada por autores como Kohan, Kennedy, Santi, Murris, que puede rendir pródigos beneficios a la disciplina completando, nunca negando, la versión analítica. Antes de dar este salto, justificaremos nuestra tesis sobre el carácter analítico de la disciplina aludiendo a los principales autores que se dedican a ella.

\section{2. bases analiticas de la Filosofía para Niños: pensar argumentativamente sobre experiencias.}

2.1. descripción y modalidades metodológicas analíticas de la Filosofía para Niños.

Una primera esquematización definitoria de esta actividad sería la siguiente: Conjunto de metodologías de promoción y mejora de pensamiento crítico, creativo y de las competencias retóricas y de oratoria en los niños y los jóvenes basada en el diálogo y en la reflexión sobre experiencias de los participantes 9

Los recursos usados por cada practicante pueden variar, pero el eje de las sesiones se repite en todos los profesionales: el trabajo lógico y conceptual acerca de vivencias particulares. Uno de los materiales de Lipman más conocidos son las narraciones que reproducen las experiencias de los niños en el medio escolar y, en ocasiones, familiar. Se utiliza el lenguaje común para plantear problemas que incentiven el diálogo. El análisis integra el estudio de las razones y del propio lenguaje y conceptos ${ }^{10}$. El análisis conceptual del lenguaje común se une al tipo de lógica que funda su teoría: la lógica informal. Por último, el pragmatismo es claro cuando se aprecia que uno de los criterios de validez del grupo es el consenso de la comunidad de investigación, auténtica arena democrática para el niño.

La necesaria adaptación a contextos específicos ha provocado que se diseñen materiales, en muchas ocasiones, ponen coto debido a las limitaciones que impone el marco estadounidense de su nacimiento. Junto a las críticas porque algunos personajes y problemáticas no se corresponden a los entornos foráneos en que se aplican, se han delineado colecciones de narraciones que se adaptan a diversos sectores de edades. En la edad infantil, localizaríamos a Angélica Sátiro y

\footnotetext{
${ }^{9}$ Síntesis personal del autor basada en su práctica particular y en las lecturas realizadas a lo largo de los últimos años.

10 Aquí, se escuchan los ecos analíticos del segundo Wittgenstein, de Austin o de Morris, cuando desde la lógica más trascendental viraron hacia el estudio de los juegos de lenguaje que aparecía por doquier en la cotidianidad. Estos juegos del lenguaje nos permite analizar las conversaciones como complejos incardinados en tiempos y espacios y listas para ser analizadas reflexivamente. Las dimensiones terapéuticas de esta filosofía se desvelan si se utiliza el término en sentido wittgensteniano, a saber entendiendo esta cura como una comprensión y especificación de los términos que se solían usar erróneamente en el mencionado lenguaje común (WITTGENSTEIN, 2008).
} 
su colección de novelas para el trabajo con niños, la Mariquita Juanita, o sus materiales para niños de 3 y 4 años (SÁTIRO 2004). Óscar Brenifier ha creado la colección de libros prácticos de las Superpreguntas donde las historias son sustituidas por preguntas sobre las cuales se trabaja dentro del aula ${ }^{11}$. Félix García Moriyón abrió un importante campo para el trabajo con jóvenes por medio de novelas actuales con materiales para el trabajo con adolescentes en la editorial española Siruela. Por otra parte, las metodologías también se han diversificado, siendo lo más habitual la sustitución de la novela o el libro tradicional por cuentos: podríamos citar las iniciativas de Robert Fisher $(2007)^{12}$, los talleres de Ellen Duthie ${ }^{13}$, los cuentos sobre Nasrudín de Oscar Brenifier (BRENIFIER, 2011, pp.165194) o los materiales de Puig y la citada Sátiro (PUIG-SÁTIRO, 2000). Asimismo, otras metodologías parten del cine, podemos rescatar en este sentido el trabajo del Grupo Iref de Barcelona (España) ${ }^{14}$. Por último, la contextualización ha provocado que se incardinen las novelas en relación a características psíquicas de algunos grupos; destacaríamos aquí las novelas editadas por Everest de María Corleone o el Diario de Ximo del programa diseñado por Sánchez Alcón "Pienso, luego soy uno más", destinado, éste último, a disminuidos psíquicos y expuesto en Pensamiento libre para personas con discapacidad intelectual (SÁNCHEZ ALCÓN, 2011). Todas las narraciones o cuentos se aderezan con guías de trabajo para que los docentes puedan desarrollar las habilidades cognitivas inherentes a este proyecto.

Al lado de estos trabajos más prácticos, las últimas décadas nos han legado investigaciones de filósofos y psicólogos que han indagado en competencias entrenadas en la filosofía para niños. Subrayamos Los niños como filósofos de Joanna Haynes (2004) y El filósofo entre pañales de Alison Gopnik (2010). La primera se acerca a un pragmatismo democratizador mencionado al comienzo de este trabajo (y que supone una importante aportación, que aquí pretendemos completar con el abordaje experiencial), pues describe la escuela como el lugar para la promoción de las competencias político-sociales que fomentan esta forma de gobierno. La orientación de la segunda es analítica con tendencias al cognitivismo, que también constituye un fabuloso aporte. En lo que sigue, concretamos desde las habilidades prácticas esta teoría.

\section{2. habilidades analiticas entrenadas.}

La influencia analítica de la Filosofía para Niños se manifiesta en las destrezas que entrenan los especialistas de esta materia.

De acuerdo con Lipman, Sharp y Oscayan (1998), las potencias que incentiva las sesiones en el aula son las siguientes: mejorar la capacidad de razonar

\footnotetext{
${ }^{11}$ La colección en España cuenta con diversos títulos editados por Edebé tales como ¿Qué es el bien y el mal?, Qué es la convivencia?, ¿Qué es la felicidad?, ¿Qué es la libertad? O ¿Qué es la vida?, entre otros.

12 Fisher, R.: Cuentos para pensar, Obelisco, Barcelona, 2007.

${ }_{13} \mathrm{Su}$ trabajo se puede consultar en la web http://filosofiadecuento.blogspot.com.es/, último acceso 10 de enero de 2016.

14 Puede consultarse su página web en http://www.grupiref.org/cat/claqueta-pensar-ambcinema.htm, último acceso 12 de abril de 2016.
} 
(LIPMAN-SHARP-OSCAYAN, 1998, pp. 129-141), desarrollo de la creatividad (LIPMAN-SHARP-OSCAYAN, 1998, pp. 143-144), descubrir alternativas (LIPMAN-SHARP-OSCAYAN, 1998, pp. 148-150), descubrir la imparcialidad (LIPMAN-SHARP-OSCAYAN, 1998, pp. 150-152) y la coherencia (LIPMANSHARP-OSCAYAN, 1998, pp. 152-155), ofrecer razones a favor de creencias (LIPMAN-SHARP-OSCAYAN, 1998, pp. 155-157), descubrir las relaciones partetodo (LIPMAN-SHARP-OSCAYAN, 1998, pp. 161-166, pp. 280-282), hacer preguntas y dar respuestas (LIPMAN-SHARP-OSCAYAN, 1998, pp 181-182; LIPMAN, 1988, p. 62), ayudar a clarificar y reformular (LIPMAN-SHARPOSCAYAN, 1998, pp. 209-211), inferir las implicaciones lógicas (LIPMAN-SHARPOSCAYAN, 1998, pp. 202-213, buscar la coherencia (LIPMAN-SHARPOSCAYAN, 1998, pp. 214-215), pedir definiciones (LIPMAN-SHARP-OSCAYAN, 1998, pp.215-216), buscar presuposiciones/asunciones (LIPMAN-SHARPOSCAYAN, 1998, pp.216-217), señalar las falacias (LIPMAN-SHARP-OSCAYAN, 1998, pp. 217-218), analizar las alternativas (LIPMAN-SHARP-OSCAYAN, 1998, pp. 222-223), agrupar ideas (LIPMAN-SHARP-OSCAYAN, 1998, p. 226), inferir, definir, concebir, asumir, hacer hipótesis (LIPMAN, 1988, p. 26). Lipman cita veintisiete habilidades que ejemplifica al final de su libro Philosophy goes to school (1988, p. 62):

\author{
1. drawing inferences from single premises; \\ 2. standardizing ordinary language sentences; \\ 3. drawing inferences from double premises; \\ 4. using ordinal or relational logic; \\ 5. working with consistency and contradiction; \\ 6. knowing how to deal with ambiguities; \\ 7. formulating questions; \\ 8. grasping part-whole and whole-part connections; \\ 9. giving reasons; \\ 10. identifying underlying assumptions; \\ 11. working with analogies; \\ 12. formulating cause-effect relationships; \\ 13. concept development; \\ 14. generalization ; \\ 15. drawing inferences from hypothetical syllogisms; \\ 16. ability to recognize and avoid - or knowing utilize- vagueness; \\ 17. taking all considerations into account; \\ 18. recognizing interdependence of ends and means; \\ 19. knowing how to deal with "informal fallacies"; \\ 20. operationalizing concepts; \\ 21. defining terms; \\ 22. indentifying and using criteria; \\ 23. instantiation; \\ 24. construction hypotheses; \\ 25. contextualizing; \\ 26. anticipating, predicting, and estimating consequences; \\ 27. classification and categorization.
}

Estas competencias se insertan en una de las siguientes tres áreas: habilidades de pensamiento (LIPMAN, 1988, p. 80), habilidades de indagación (LIPMAN, 1988, p. 80) y habilidades de formación de conceptos (LIPMAN, 1988, p. 80-81). Todas remiten a capacidades cognitivas. 
Oscar Brenifier concluye que el quehacer de la filosofía se concreta en tres grupos, que forman el triángulo del trabajo dentro de las aulas: identificar, criticar y conceptualizar. La identificación consiste en (1) reconocer las fronteras de un ente y (2) separarlo de aquello que no es; por ejemplo, determinar que la fruta que tengo en la mano (1) es una manzana y (2) no es una pera o un plátano. La crítica consiste en problematizar y en analizar hipótesis y conceptos, es decir, poner en duda lo dado y estudiar la potencia argumentativa de las (hipo)tesis no demostradas. La conceptualización insta a averiguar cuál es el concepto específico que se corresponde a una situación y a sistematizarlo (BRENIFIER, 2011, p. 43-44).

Brenifier agrega a estas tres habilidades cognitivas cerca de treinta más que agrupa en tres bloques:

\section{Intelectual: pensar por sí mismo}

- Proponer conceptos e hipótesis.

- Estructurar, articular y clarificar las ideas.

- Comprender las ideas de los demás y las de uno mismo.

- Analizar.

- Reformular o modificar una idea.

- Trabajar la relación entre el ejemplo y la idea.

- Argumentar.

- Practicar la interrogación y la objeción.

- Iniciación a la lógica: relación entre los conceptos, la coherencia y la legitimidad de las ideas.

- Desarrollar el juicio.

- Utilizar y crear instrumentos conceptuales: error, mentira, verdad, absurdo, identidad, contrarios, categorías, etc.

- Verificar la comprensión y el sentido de una idea.

Existencial: ser uno mismo:

- Singularizar y universalizar el pensamiento.

- Expresar y asumir su identidad personal a través de sus elecciones y nuestros juicios.

- Ser consciente de uno mismo, de sus ideas y de su comportamiento.

- Controlar sus reacciones emocionales.

- Trabajar su forma de ser y pensamiento.

- Interrogarse, descubrir y reconocer el error y la incoherencia en uno mismo.

- Ver, aceptar, verbalizar y trabajar sus propios límites.

- Distanciarse de su forma de ser, de sus ideas y de uno mismo.

Social: pensar con otros:

- Escuchar al otro, proporcionarle su espacio, respetarlo y comprenderlo.

- Interesarse por el pensamiento del otro: descentrarse por medio de la reformulación, de las preguntas y del diálogo.

- Arriesgarse e integrarse en un grupo; permitir que los otros nos pongan a prueba.

- Comprender, aceptar y aplicar las reglas de funcionamiento.

- Discutir las reglas de funcionamiento.

- Responsabilizarse: modificación del estatus del alumno frente al maestro.

- Pensar con los otros, en lugar de competir con ellos (BRENIFIER, 2011, p. 132-133)

Ha de indicarse que el autor francés mezcla en este listado habilidades cognitivas, como "analizar" o "argumentar", con competencias relativas a 
actitudes o disposiciones de ánimo, como "controlar las reacciones emocionales", y con normas o mandatos, como "escuchar al otro". Las primeras poseen suficiente claridad para poderse entrenar; sin embargo, resulta confuso cómo mejorar las disposiciones ${ }^{15}$ de ánimo; por último, las normas no son objeto de mejora personal sino de seguimiento de reglas de juego que no se aprenden, sino que se aceptan o no. Por eso, vuelven a quedar las habilidades cognitivas como nudo gordinano práctico de la formación obtenida en las sesiones de Filosofía para Niños.

Eugenio Echeverría, que difunde la Filosofía para Niños desde inicios de los años noventa en México, es un gran defensor de la metodología lipmaniana por lo que las habilidades que propone suscriben las propuestas del norteamericano. Concretamente, inventaría las siguientes:

- Dar razones.

- Distinguir las buenas razones de las malas.

- Construir inferencias y evaluar argumentos.

- Generalizar y usar analogías (razonamiento inductivo).

- Identificar, cuestionar y justificar supuestos.

- Reconocer contradicciones.

- Detectar falacias.

- Procurar la consistencia.

- Hacer distinciones y conexiones (parte/todo, medios/fines, causa/efecto).

- Hacer preguntas y hallar problemas.

- Discutir con base en los intereses comunes de lo involucrados.

- Saber escuchar a los demás.

- Hacer predicciones, formular y probar hipótesis.

- Proponer ejemplos y contraejemplos.

- Corregir el propio pensamiento.

- Formular y usar criterios.

- Detectar vaguedades y ambigüedades.

- Pedir evidencias.

- Tomar en cuenta todas las consideraciones relevantes.

- Tener apertura mental y ser imaginativo.

- Desarrollar coraje intelectual, humildad, tolerancia y perseverancia.

- Estar comprometido con la búsqueda de la verdad.

- Ser cuidadoso con los procedimientos de indagación.

- Respetar a las personas y sus puntos de vista (ECHEVERRÍA, 2006, p. 155)

Suma a este inventario un gráfico donde escinde en cuatro grupos las habilidades de pensamiento que ocupan las sesiones, a saber, habilidades de razonamiento, de indagación, de formación de conceptos y de traducción y transferencia. Los tres primeros grupos vuelven a apelar a competencias analíticas como estandarizar, crear alternativas o definir. Echeverría añade algunas disposiciones que aluden al desarrollo de algunas disposiciones: "saber escuchar",

15 Entendemos disposición como la capacidad ontológico-geográfica de situarse de un modo determinado. Esta localización da lugar a un tipo de acciones y decisiones específica. Por ejemplo, la disposición emprendedora cataliza la generación de proyectos mientras que la disposición temerosa incapacitaría a ellos. La disposición de ánimo no se aprende sólo mediante una técnica sino que requiere una reflexión y haber pasado por experiencias que nos conduzcan a ella. 
"tener imaginación moral", "respetar a los demás", "poner el ego en perspectiva", entre otras (ECHEVERRÍA, 2006, p.57). Como en Brenifier, no se explicita el medio de alcanzarlas, puesto que su aprehensión depende no sólo de trabajos analíticos o técnicos sino de abordajes relativos al estado de ánimo.

Carla Carreras, directora del Master on-line de Filosofía para Niños en la Universidad de Girona, se afianza en el esquema analítico cuando resume las habilidades de pensamiento de nuestra profesión por medio del siguiente cuadro:

\begin{tabular}{|c|c|c|c|}
\hline \multicolumn{4}{|c|}{ HABILIDADES DE PENSAMIENTO } \\
\hline $\begin{array}{c}\text { Habilidades } \\
\text { de } \\
\text { investigación }\end{array}$ & $\begin{array}{l}\text { Habilidades de } \\
\text { análisis o de } \\
\text { conceptualización }\end{array}$ & $\begin{array}{c}\text { Habilidades de } \\
\text { razonamiento }\end{array}$ & Habilidades de traducción \\
\hline $\begin{array}{c}\text { Informan sobre } \\
\text { el mundo }\end{array}$ & $\begin{array}{l}\text { Organizan la } \\
\text { información }\end{array}$ & $\begin{array}{l}\text { Amplían el conocimiento } \\
\text { con el solo uso de la razón }\end{array}$ & $\begin{array}{r}\text { Explicitan } \\
\text { formulan el re } \\
\text { conoci }\end{array}$ \\
\hline $\begin{array}{c}\text { Formular } \\
\text { hipótesis } \\
\text { Descubrir } \\
\text { Observar } \\
\text { Buscar } \\
\text { alternativas } \\
\text { Anticipar } \\
\text { consecuencias } \\
\text { Seleccionar } \\
\text { posibilidades } \\
\text { Imaginar } \\
\text { etc. } \\
\end{array}$ & $\begin{array}{c}\text { Formular conceptos } \\
\text { precisos } \\
\text { Poner ejemplos y } \\
\text { contraejemplos } \\
\text { Hallar semejanzas y } \\
\text { diferencias } \\
\text { Comparar y } \\
\text { contrastar } \\
\text { Definir } \\
\text { Agrupar y clasificar } \\
\text { Seriar } \\
\text { etc. }\end{array}$ & $\begin{array}{c}\text { Buscar y dar razones } \\
\text { Hacer inferencias } \\
\text { Razonar condicionalmente } \\
\text { Razonar analógicamente } \\
\text { Establecer relaciones de } \\
\text { causa y efecto } \\
\text { Establecer relaciones entre } \\
\text { las partes y el todo } \\
\text { Establecer relaciones entre } \\
\text { los fines y los medios } \\
\text { Evaluar } \\
\text { etc. }\end{array}$ & $\begin{array}{l}\text { Explicar: narrar y describir } \\
\text { Interpretar } \\
\text { Improvisar } \\
\text { Traducir del lenguaje oral a } \\
\text { la mímica y viceversa } \\
\text { Traducir del lenguaje oral a } \\
\text { la plástica y viceversa } \\
\text { Traducir a diferentes } \\
\text { lenguajes } \\
\text { Resumir } \\
\text { etc. }\end{array}$ \\
\hline
\end{tabular}

Fuente: CARRERAS, Carla. "Filosofía para Niños: el desarrollo global de la habilidades de pensamiento" en BARRIENTIS RASTROJO, 2013, p. 99.

Walter Kohan, teórico argentino de la Filosofía para Niños, es quien más se aleja de la visión analítica, proponiendo críticas y avances interesantes frente a Lipman y se inclina a desplegar ciertas disposiciones en el niño ajenas a la analítica. Para ello, critica la visión lipmaniana indicando como ejemplares del mismo las siguientes habilidades:

Vamos a ejemplificar algunas de las prácticas que constituyen las comunidades de investigación propuestas por Lipman. Entre otras, escuchar con atención a los miembros de la comunidad; apoyar a los otros participantes ampliando y corroborando sus puntos de vista; someter los puntos de vista de los otros participantes a la investigación conjunta; dar razones para apoyar los puntos de vista de los demás aun cunado se esté en desacuerdo con ellos; colocar el ego en perspectiva; responder a los otros, alentar a las otras personas de la comunidad a expresar sus puntos de vista; contribuir para el crecimiento de la autoestima de los otros miembros del grupo: cuidar no sólo los procedimientos lógicos sino el crecimiento de los otros miembros de la comunidad; estar abierto a cambiar los propios puntos de vista y prioridades en relación a los puntos de vista de los otros integrantes de la comunidad; desarrollar la confianza mutua; cultivar prácticas de cooperación y solidaridad en la construcción comunitaria del saber y en el reconocimiento de la mutua dependencia (KOHAN;WAKSMAN, 2000, p. 23) 
A pesar de la apertura que nos manifiesta este texto respecto a la progresión del niño en criticidad, el objetivo principal de Lipman sigue siendo la consecución de estudiantes que optimicen sus capacidades analíticas. Se construye sobre la asunción, de tendencia lipmaniana, de que este perfeccionamiento lógico influirá sobre la totalidad del sujeto, creyendo que los individuos más críticos serán más éticos, esto es, desarrollarán una moral más consciente y responsable. Nosotros presentamos serias dudas sobre este argumento: existen personas con una sobresaliente agudeza intelectiva que la utilizan para fines delictivos o lesivos para la comunidad.

Nosotros defendemos que la mejora del sujeto se sitúa en sobre procesos de reflexión, pero, sobre todo, de vivencias que abran al niño y al adolescente a comprensiones nuevas de la realidad. Una reflexión conceptual sobre la infame situación de los pobres en África no siempre induce a actitudes donativas en los oyentes, pero marchar a aquellas tierras durante un año y convivir con ellos traslada a un cosmos que hace más proclive al compromiso social. Levinas, autor continental, lo explicaba con elocuencia: "el rostro se me impone sin que pueda hacerme sordo a su llamada, ni olvidarlo, quiero decir, sin que pueda dejar de ser responsable (de) a su miseria" (LEVINAS, 1993, p. 91). Trabajar sobre la apertura experiencial (antes que, o además de, sobre la reforma de los procesos analíticos) conduciría a las disposiciones citadas por Kohan y Waksman más arriba.

Las razones de lo anterior se aclaran dentro del imaginario orteguiano: es preciso diferenciar el quehacer sobre las creencias y el que se ejerce sobre las ideas. Las creencias (que nos constituyen) fundan las ideas (que poseemos). Por tanto, si se pretende una metamorfosis ontológica, ¿no sería más útil trabajar sobre las primeras con el fin de una mutación profunda del niño? Siendo éste el caso, habría que indagar en las formas de herirlas; aquí entra en juego la superación de la experiencia sobre el análisis lógico-conceptual. El itinerario propuesto para nuestra área se explicita en el título de la asignatura que se ocupa de estos temas en la Universidad de Sevilla: "Filosofía para Niños. Aprender a ser". El objetivo es ontológico y no sólo técnico, metodológico y cognitivo.

\section{3. limites de la aproximación analítica.}

La filosofía analítica y el logicismo han apostado por la fusión entre la ontología, el pensamiento y el lenguaje. El maridaje entre racionalidad y realidad sienta las bases para un positivismo donde el sujeto quedaba determinado por la constricción racionalista: la realidad podría codificarse íntegramente bajo estructuras lógicas y todo aquello que no se insertase en este esquema no poseía carta de autonomía para existir. Es más, la razón constituiría la base de la antropología, por lo que, aseverarían, una modificación de las ideas acarrearía una mutación nodal de la persona.

A pesar de los argumentos de filósofos de la sospecha como Nietzsche, Freud o Marx y de las suspicacias respecto a la hegemonía de la racionalidad argumental de autores como Scheler, Heidegger o Zambrano, el neopositivismo y el empirismo lógico permanecerán aferrados durante gran parte del siglo XX al punto arquimédico con que comenzaba este epígrafe; no obstante, diversas 
evidencias prácticas dudan respecto a esta posición. Nosotros traemos un par de ellas.

La novela Quando Nietzsche chorou escrita por Irvim Yalom relata la historia ficticia de la cura filosófica de Breuer, maestro de Freud, por medio de Nietzsche. El autor de así habló Zarathustra ejerce funciones de orientador filosófico con Breuer usando la filosofía. A pesar de los esfuerzos por un uso continental, los resultados son analíticos, es decir, inciden únicamente sobre las ideas. Breuer se queja de los esfuerzos conceptuales de su compañero: las palabras y la vida corren por senderos diversos, no siempre es suficiente el trabajo argumentativo para tocar la existencia. En sus propias palabras, señala:

"He aquí una verdad con una racionalidad suprema e irrefutable. Sin embargo, cuando estoy verdaderamente asustado, ella no funciona, nunca calma mis temores. Ese es el fallo de la filosofía. Enseñar filosofía y aplicarla en la vida real son empresas bastante diferentes". (YALOM, 2007, p. 220).

Las desavenencias entre pensar argumental, hacer y ser no conforman una innovación en este escrito, pueden rastrearse en textos bíblicos que datan de casi veinte siglos atrás. Pablo de Tarso atestiguaba la contradicción entre su querer racional y su hacer ontológico en la Carta a los romanos: conocía las acciones más santas, pero materializarlas no dependía exclusivamente del conocimiento teórico y fundamentado; así, se quejaba con una máxima clásica: "no hago el bien que quiero sino el mal que no quiero, eso hago” (Rm 7, 19). Volición y razón recorrían sendas opuestas.

Con esto, no concluimos que sentarse con un niño a reflexionar sobre una mala acción de la que es responsable sea inútil. Es posible esgrimir circunstancias que ponen de manifiesto los beneficios de una reflexión argumentada sobre las consecuencias de los propios actos. Ahora bien, el hecho de que una misma conversación igualmente bien asentada en razones de lugar a una mutación ontológica en un niño y no en su compañero, debería hacernos pensar si la eficacia no escapará a la excelencia del tramado lógico de la conversación.

La metamorfosis ontológica, o el cambio de la persona, sostenemos, no descansa (exclusivamente) en la excelencia de la composición del argumento sino en la potencia para que el intercambio se haya convertido en una experiencia.

El esquema analítico se basa en el siguiente gráfico: 


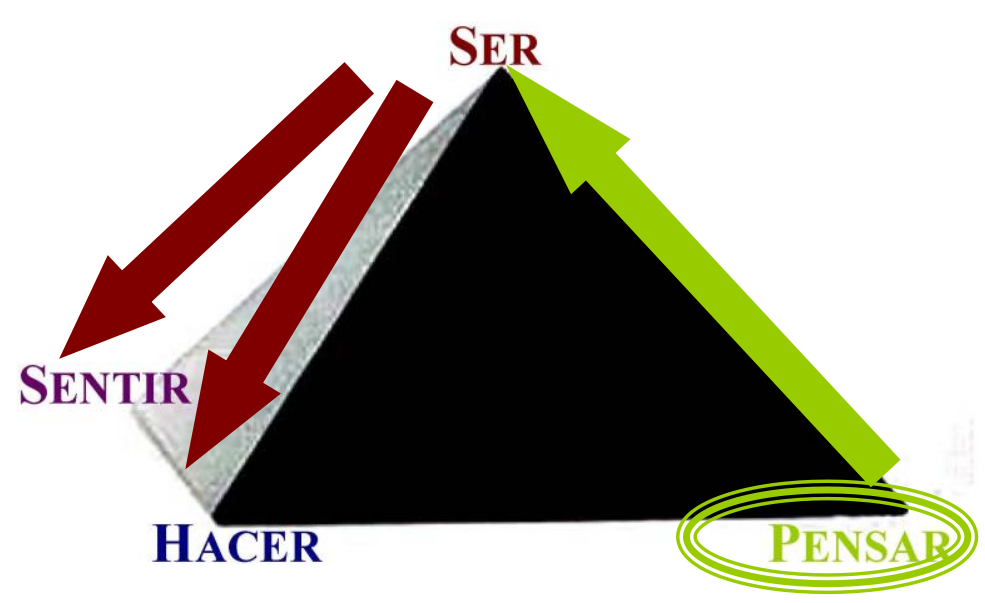

Aquí, el trabajo realizado sobre el pensamiento del niño incidiría sobre lo que es $\mathrm{y}$, como consecuencia $\mathrm{y}$ en un segundo paso, mutarían todas las dimensiones de la persona, a saber, su volición-hacer, su afección-sentir u otras que podamos imaginar.

El problema es que, como hemos visto, esto no siempre es así sino que se cortocircuita la flecha que une el pensamiento y el hacer: como en el caso de Pablo de Tarso, se conoce la mejor decisión pero el comportamiento no es coherente con él.

La solución pasaría por generar una acción directa sobre el ser evitando el momento previo y consiguiendo que se cumpla el croquis que sigue:

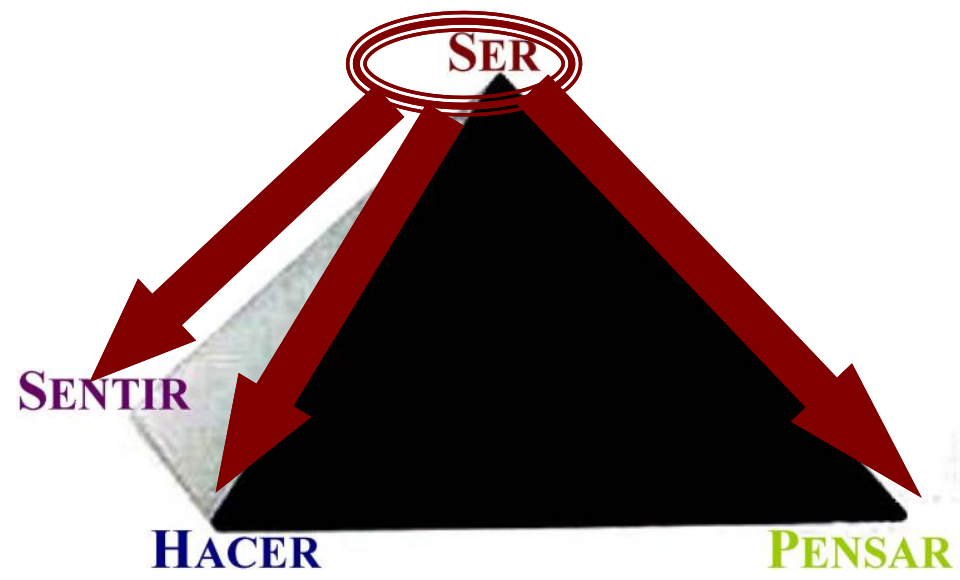

Si aplicamos este gráfico al desempeño de los especialistas en Filosofía para Niños, el objetivo dentro del aula debería centrarse en influir sobre ser y no en el pensar, o bien potenciar un tipo de trabajo lógico que no genere fisuras entre lo ontológico y lo cognitivo. No cabe duda que una de las formas básicas para mejorar nuestro ser es la razón argumental, pero la filosofía nos ha enseñado que, junto a ésta, se despliegan otras como la razón simbólica, la razón poética, la razón mística o la razón amorosa. Todas ellas actúan sobre el ser del sujeto y son las causantes de que, en ocasiones, las consecuencias del pensar analítico (las buenas 
acciones que se conocen) y la vida (las voliciones concretadas que son deudoras de otras racionalidades) recorran senderos no armónicos.

Repitámoslo: proponemos como razón nodal que hiere al ser y la transforma de modo directo es la experiencia, porque la vida del sujeto se arma en base a experiencias se enmarquen éstas en lo analítico, en lo simbólico, en lo poético o en lo místico, entre otros. La conexión ser-experiencia ${ }^{16}$ es directa porque toda verdadera experiencia es metamórfica, algo que no siempre puede decirse de la conexión ser-argumentar.

\section{3. bases experienciales de la filosofía para niños.}

\section{1. disclaimer o descargo de cargos inicial.}

La presentación de esta teoría en conferencias y paneles de discusión de Filosofía para Niños y de Filosofia Aplicada ha resultado muy útil para comprender cómo puede malentenderse. Así, responderemos a los dos equívocos más comunes.

Cuando hemos defendido un abordaje experiencial de la Filosofía para Niños algunos autores nos han recordado que la experiencia es un nudo gordiano no sólo en Lipman sino también en Dewey. Las novelas lipmanianas se alzan sobre narraciones de experiencias muy cercanas al niño porque el objetivo es reflexionar sobre circunstancias vividas en su cotidianidad. De hecho, esta sería la diferencia con respecto a la, así definida, filosofía académica, la cual se enlodaría con temas abstractos ajenos al día a día ${ }^{17}$. Nuestra teoría no anima, únicamente, a reflexionar sobre experiencias sino a que la experiencia se constituya en agente y catalizador para la transformación del niño; si se quiere, incentivamos el cambio desde la experiencia y no desde la reflexión sobre la experiencia. La actualización (puesta en acto) de la experiencia sumerge al niño en un marco diferente que lo traslada a comprensiones de la realidad diferentes. Estas comprensiones son debidas a un cambio radical de su forma de ser. Por ejemplo, el fuerte apego de un niño a sus padres puede generarle pensamientos y sentimientos negativos sobre los demás, a sentir el abandono cuando sus progenitores no están a su lado y a llantos desconsolados en el momento de la separación. La forma analítica de limitar estos efectos es mediante conversaciones con sus propios padres. El medio experiencial anima a introducir al pequeño en un orbe nuevo de forma no violenta (la violencia imposibilitaría la apertura a la experiencia puesto que clausura en torno al, marco anterior por el miedo que le generaría la experiencia). Por ejemplo,

\footnotetext{
${ }^{16}$ Como se verá más adelante, todas las experiencias nos transforman, pero no todas las vivencias consiguen iguales resultados. Las experiencias no son cada una de las circunstancias por las que transitamos en el día a día, eso son vivencias, en nuestro modelo, sino que consisten en aquellas vivencias que por razones internas a la circunstancias y por aperturas del ser que la vive permiten infiltrarse en el individuo provocando las citadas reformas antropológicas.

${ }^{17}$ Esta explicación de la escisión es bastante débil a la luz de la historia del pensamiento. No nos detendremos en ello puesto que puede consultarse nuestra ponencia "O que é a filosofia aplicada. Abordagem hermenêutico-gadameriano e crítico-freiriano" expuesta en la Universidade Católica Portuguesa en febrero de 2014 o nuestro texto "A recuperação do ser pela palavra como meio de (re)conciliación entre a Filosofia Aplicada e a Filosofia Acadêmica" (BARRIENTOS-RASTROJO, 2014a).
} 
la madre acompañaría a su hijo al colegio con una progresiva deshabituación y apertura a las posibilidades del otro de forma positiva.

Ambas estrategias pueden llevarse a término, pero resulta más crucial la segunda, puesto que una conversación no siempre obtiene los efectos deseados, mientras que una auténtica experiencia (no vivencia), manejada con la habilidad aperturista que exige, desencadena siempre la transformación del sujeto. Es más, la eficacia del abordaje analítico se incentiva en la medida en que la discusión o indagación argumental se convierte en una experiencia. En esos casos, la palabra pasa de ser un medio de transmisión de información a punto de partida de palpitante experiencia ${ }^{18}$.

Durante una conferencia impartida en 2013 en la Universidad de Évora en la I Jornada Internacional de Filosofia para Crianças, una profesora del público realizaba una excelente crítica a nuestro planteamiento. Nos sugería que le había parecido que nuestra visión analítica reducía el concepto de razón a modelos cartesianos excesivos. Sin embargo, añadía, la razón también podía ser sentimental o sentiente, tal como demostraba Zubiri (ZUBIRI, 2004). Como puede intuirse, nosotros no nos oponemos a que el análisis racional incluya también contenidos emocionales. El problema radica en que la metodología analítica se mantiene aun cuando el objeto cambie. La vertebración analítico-argumental permanece aun cuando el tema de la sesión es el amor de los padres o las consecuencias de la discusión con un compañero. La aproximación experiencial, por el contrario, se incardina en una labor ontológica, puesto que lo crucial no es la reflexión sobre el sentimiento sino la generación de una situación provocadora de experiencias que obligan a ser otra persona. Por otra parte, la propuesta que realizamos no quiere ubicarse en una topología ontológica (la razón), en dos (la razón y la emoción) o en más, sino que pide un abordaje holístico (la transformación del sujeto). Por tanto, si hacemos bascular la metodología desde el pensamiento a trabajos emocionales, ¿no se caería en el mismo peligro de fisura entre una dimensión y el ser completo? Por último, los modelos que hablan de quehaceres sobre el pensamiento, el sentimiento o sobre otras dimensiones humanas se alzan sobre un esquema modernista: se cita la transformación autónoma (o ayudado por otro) de mi pensamiento o de mis sentimiento, como si estuviera en nuestra mano su metamorfosis completa. Ahora bien, ¿y si en esa transformación somos más receptores que agentes?, ¿y si la creación de una actitud amorosa o inteligente fuera resultado no (sólo) de nuestra voluntad sino de la disposición a abrirnos a aquello que la produce, a saber, el amor o la inteligencia?

\section{2. la experiencia' ${ }^{19}$.}

18 En este sentido, la Filosofía Aplicada Experiencial requiere un estudio continental desde los abordajes realizador por autores como Zambrano (ZAMBRANO, 1989; ZAMBRANO, 1993) o Gadamer (1998).

19 Este punto ha sido extraído de la obra conjunta que publiqué con Mauricio Beuchot La Filosofía Aplicada desde la Hermenéutica Analógica (BEUCHOT; BARRIENTOS-RASTROJO, 2013, pp. 123-126). El contenido de este epígrafe puede ampliarse en los siguientes artículos: BARRIENTOSRASTROJO, 2010, 2011. 
La experiencia consiste en la vivencia (o padecimiento) intensa de un suceso que impacta provocando un cambio ontológico, es decir causa un cambio en el modo de ser de la persona. Por ello, se trasladará a todas las dimensiones antropológicas como las olas del agua cuando cae una piedra en medio de un lago.

Las imágenes asociadas a este concepto son las del viaje iniciático, tal y como queda signado en su etimología, pues la raíz de experiencia se encuentra en "per"; " per se trata originariamente de viaje, de caminar por el mundo cuando no había caminos, sino [cuando] todo viaje era más o menos desconocido y peligroso. Era el viajar por tierras ignotas sin guía previa" (ORTEGA; GASSET, 1994, p. 176), esto es, realizar el propio camino e, inversamente, construirse a uno mismo en este itinerario Los viajes de Ulises son una muestra de este fenómeno: escanciaban mutaciones en el héroe que permitían entender que quien zarpaba y quien regresaba eran seres distintos. He aquí la fuerza ontológico-antropológica del viaje experiencial: la metamorfosis identitaria. Ortega y Gasset realiza un segundo enlace etimológico, "per" con "portus", pues la expedición existencial conlleva cruzar puertas. Sus batientes no permiten el paso atrás. El descubrimiento de ciertas verdades ocultas al inicio es el causante de que la persona no pueda seguir siendo el mismo ${ }^{20}$.

Según López Aranguren, la verdad extraída de esas experiencias se distingue del conocimiento teórico, del conceptual o del argumental por varias razones.

La experiencia de la vida es, pues, el saber adquirido, viviendo [...]. No es el saber estudiado y aprendido, ni tampoco el ideado o construido. No es un saber intelectual, sino vital. $Y$, por otra parte, es saber personal, no tradicional, heredado o sapiencial (LÓPEZ ARAGUREN, 1966, p. 36)

Para Zambrano, el conocimiento experiencial es un saber trágico "que se adquiere padeciendo el conflicto hasta apurarlo" (ZAMBRANO, 1986, p. 79).

Entiendo por experiencia el saber trágico - que Zeus había de aprender padeciendo-. Según Santo Tomás, la mística ¿no es el conocimiento experimental de Dios? Pues en eso estamos queramos o no queramos. Y una servidora añade siempre: «recibiéndolo» pasivamente, y padeciendo activamente (ZAMBRANO, 2002, p. 80)

Zubiri perfila este rostro al distinguir el asiento intelectual del conocimiento del experiencial de estas verdades, pues el segundo pide un "comercio efectivo con las cosas" y no sólo una comprensión intelectiva sobre la realidad: "Experiencia significa algo adquirido en el transcurso real y efectivo de la vida. No es un conjunto de pensamientos que el intelecto forja, con verdad o sin ella, sino el haber que el espíritu cobra en su comercio efectivo con las cosas". (ZUBIRI, 1940, p.189)

En síntesis, el saber experiencial abarca un movimiento (la aprehensión de realidad realizada por el individuo) y un resultado (los saberes que se apropian de un espacio propio en la volición, la afectividad y el pensamiento). Por ello, este saber es más radical que el lógico-argumental, esto es, nace de un nivel más

\footnotetext{
${ }^{20}$ De aquí que la experiencia se vincule también con el concepto de anagogía (ANTÓN, 2010, pp. 151-152 y 168).
} 
profundo, de la raíz metafísica del sujeto. Ésta es la razón de que apelemos a él en una acción que ansía no sólo influir en las ideas sino en la totalidad del sujeto.

Hace un lustro, diseñamos la siguiente definición del saber de la experiencia basándonos en los planteamientos de María Zambrano. En ella, destacamos propedéuticamente la secuencia por la que se obtiene.

El saber de la experiencia consiste en el sumatorio de los conocimientos teóricos, la puesta en práctica de los mismos, las evidencias extraídas del acto de materializar en la propia vida las informaciones citadas, la reflexión posterior de lo acontecido (de los hechos vividos y las emociones conclusivas) y la cristalización del conocimiento en máximas y en ideas que se saben como verdad (BARRIENTOS-RASTROJO 2010, p. $555)$

Aunque, actualmente, matizaríamos algunos elementos (por ejemplo, cambiaríamos "sumatorio" por "integración") y añadiríamos otros (como la necesidad de una epistemología anagógica), esta descripción nos sirve como aproximación para enlazar con los elementos necesarios para capturar este tipo de saber.

\section{3. exigencias para la aprehensión experiencial21.}

Si el saber analítico obliga a aprender una serie de técnicas para alcanzar conclusiones justificadas legítimas y para distinguirlas de las resultantes de argumentos falaces o errados, el experiencial se centra en la adquisición de disposiciones de apertura y de arrojo para que se materialice. Estos criterios, que resumimos a continuación, marcan el camino para distinguir y jerarquizar las auténticas verdades experienciales de las incorrectas o falaces y para detectar los auténticos agentes de aquellos que usan la impostura del sabio desde un fondo vacío.

(1) arrojo frente a la visión del peligro y coraje para atravesar las puertas.

Una etimología de "ex-periencia", no mencionada arriba, se asocia con "peiro", que significa peligro. Quien rehúsa cruzar el Rubicón por el miedo a la caída no adquiere el saber inherente a la prueba, puesto que no realiza el viaje. El aprendizaje experiencial no huirá de tener que ejercer ciertos niveles de valentía y arrojo pues sin ellos la visión ante el riesgo del naufragio existencial solo conduce a un espanto paralizante.

El piélago del mar bravío muestra un infinito inabarcable y preludia una pérdida; consecuentemente, muchos se arredran y deciden no atravesar tales proscenios. Vadear estos caminos tiene un coste existencial de primera magnitud: la pérdida del propio ser, del ser previo; como en todo nacimiento, habrá sufrimiento y dolor o, al menos, incomodidad y obligación a salir del confort del día a día. Sin embargo, sin éxodo, no hay madurez. Por todo ello, al arrojo habrá que sumarle un ánimo elevado como el que acompaña al coraje.

${ }^{21}$ Hemos desarrollado el concepto de experiencia y las disposiciones que la facilitan en varios trabajos (BARRIENTOS-RASTROJO, 2013; 2015a; 2015b). 
(2) agudeza o sutileza.

Las evidencias del saber de la experiencia dependen del desarrollo de capacidades intuitivas. Esta intuición permite que el maestro vea verdades con mayor premura y destreza que el alumno. La adquisición de esta capacidad no es técnica sino que requiere la convivencia con aquel que la posee, la asistencia a un taller particular que es más semejante al del artista que enseña a cincelar la escultura a sus discípulos que a un aprendizaje memorístico de un contenido. Mauricio Beuchot ha explicado perfectamente este tipo de aprendizaje en relación al arte hermenéutico:

Creemos -con MacIntyre- que dicha formación tiene el aspecto de una comunidad de investigación. Vamos más allá. Creemos que tiene la forma de un taller de artista o de artesano. Al taller entramos como aprendices, para trabajar con un maestro y aprender de él y de los demás alumnos el arte del que se trata. Así, se adquiere el arte de la interpretación. Puede que alguien sea buen hermeneuta de manera innata, como hay también buenos poetas o buenos oradores por naturaleza; pero el estudio los hará mejorar. Y mucho más el estudio compartido, dentro de una comunidad hermenéutica o escuela (BEUCHOT; ARENAS; DOLZ, 2008, p. 80)

(3) paciencia y humildad para aceptar el método de la sierpe antes que atajos que ocultan parte de la realidad.

La reflexión filosófica no sería posible sin una escucha atenta, paciente y humilde. La atención exige apertura plena a lo que nos rodea. A diferencia de las metodologías técnicas de la modernidad, el camino del saber de la experiencia no sigue un sendero directo, nítido y con un objetivo claro desde el comienzo; este conocimiento requiere la caída y el hundimiento en la realidad para capturar su totalidad. Esa caída lleva a sumergirse y dejarse llevar por una realidad que se hace dueña del individuo; éste entra en contacto con sus raíces no de modo racional sino desde la conexión directa con estas bases originarias, puesto que se funde con lo dado22.

La persona paciente apremia a la realidad para que se manifieste en base a tiempos y protocolos que hayan de cumplirse; por el contrario, acepta que los entes florezcan de modo gracioso, gratuito y cuando así lo determine su propia naturaleza. $\mathrm{Al}$ otro lado, las modalidades metodológicas, como el conocimiento científico, siguen un plan pautado que obliga al proceso de conocimiento de la realidad y a la realidad misma a ajustarse a sus dictados; así impone moldes al objeto con lo que se oculta parte de éste, puesto que lo que aparece es el lado del mismo permitido por la particular aproximación metodológica de la estrategia utilizada.

Por su lado, la humildad alienta a reconocer la pequeñez humana y, casi, a derogar la idea de que éste posea algún poder para obligar al nacimiento de la

\footnotetext{
22 Sobre los modos de alcanzar estos arquetipos y sobre su naturaleza, hemos escrito Los símbolos desfallecidos (BARRIENTOS-RASTROJO, 2014b).
} 
verdad del objeto. La flor sólo puede abrirse cuando ella lo decida, pues si el individuo intenta hacerlo por sus propios medios sólo conseguirá destruirla.

La escucha atenta, la paciencia y la humildad asumen que el acceso a los entes no es un camino definido previamente sino que, con frecuencia, su forma es serpentina y no recta. De hecho, el método lo crea el objeto a conocer. Debido a esto, el conocimiento experiencial incluye la percepción por parte del cognoscente tanto avances como retrocesos, puesto que de ambos se destilan verdades. Las técnicas aquí son útiles, pero no suficientes.

(4) Disponibilidad de un retiro no solipsista.

El retiro aparta de distracciones. Sin embargo, un exceso de celo anacoreta oculta los contenidos tributarios del intercambio con otras personas. El contacto dialéctico con otros origina conocimientos de cuya destilación se obtienen saberes experienciales. En suma, el retiro anima a disponer de momentos de recogimiento para la reflexión, pero no debe constreñir a un confinamiento en torres de marfil inexpugnables (COMTE-SPONVILLE, 2000, p.29).

(5) Compromiso con la autenticidad en lugar de huir.

El descubrimiento de hitos y características personales no laudables lesiona el yo, por lo que no debe extrañar que fomenten la huída o el alejamiento de la mirada respecto a la propia debilidad. Asimismo, la confianza petulante ante un ego que no mira su limitación también provoca defectos de visión existencial. Estas carencias en la visión impiden la maduración existencial del conocimiento que aquí estudiamos. El remedio a tal deficiencia es el compromiso con la autenticidad, aun cuando ser testigos de muchos de sus discursos sea una acción sumamente dolorosa.

(6) Capacidad para abrirse a la realidad de los entes más allá de sus notas pragmáticas.

El saber de la experiencia capacita para una aprehensión diferente a la pujante en la contemporaneidad occidental, a saber, un pragmatismo que oculta la ontología bajo una consideración utilitarista de todos los entes.

Heidegger ha bosquejado dos formas de dirigirse a la realidad por medio del ejemplo de unas botas vistas por un campesino y por un pintor. El primero las intelige utilitaristamente: las botas son aquello que sirve al labriego para un fin específico; la segunda, contemplativamente: el significado de unas botas emerge desde ellas misma, no hay que imponerles un sentido sino dejarlas que ellas resumen su esencia. Por eso, concluye, "ha sido la obra de arte la que nos ha hecho saber lo que es de verdad un zapato" (HEIDEGGER, 2001, p. 23). El filósofo debería superar la primera con el fin de comprender la realidad quedando a la escucha del objeto y no obligando a que ésta se amolde a las propias metodologías.

Todas estas notas nos dan idea del tipo de sujeto a conseguir en las sesiones filosóficas y de los universos sobre los que se ha de incidir: la promoción de virtudes como la valentía y la humildad y de competencias como la agudeza o sutileza hermenéutica para ver más allá de la superficie doxológica. Enfatizar estas disposiciones (y otras que aparecerán en un libro sobre la filosofía experiencial), ayudan a que una vivencia se transforme en una experiencia. 
La diferencia entre vivencia y experiencia muestra cómo el saber de la experiencia no depende de haber vivido mucho (o muchos años) sino de que hayamos permitido convertirse a muchas experiencias en nuestras maestras existenciales. Cotidianamente, vivimos coyunturas de forma voluntaria o involuntaria: el almuerzo con nuestra pareja, la pelea con un compañero de trabajo, el acto de pagar el billete del metro, ducharnos, conducir nuestro coche, visitar una sala de conciertos, etc... La repetición de cada una de esas actividades no suelen dejan una huella en nuestra existencia, ni cada una de ellas se mantienen indelebles en nuestro recuerdo o son las causantes de una nueva forma de ver la vida. Quizás, no nos acordemos de la composición de nuestro menú de ayer, pero atesoramos el recuerdo de la primera vez que comimos una ensaimada en Mallorca o una francesinha en Oporto; tal vez, no recordemos el nombre de todos nuestros profesores de primaria, pero guardamos con estima la imagen de aquel que durante meses nos ayudó gratuitamente a mejorar nuestras competencias lectoras. Las vivencias son muchas, pero sólo unas pocas se transforman en experiencias, aquellas que conforman nuestra auténtica historia espiritual $u$ ontológica, nuestra biografía y nuestro ser. Si la Filosofía para Niños es un aprendizaje para ser, ¿no tenemos aquí un punto de partida nuevo para materializar otra forma de hacer Filosofía para Niños?

Una Filosofía para Niños Experiencial se dedicaría a estudiar cómo incentivar (o limitar) las experiencias en la infancia y, con ello, alcanzar verdades que no sólo apelan a la mente sino a la totalidad humana.

\section{4. breve apunte del funcionamiento ontológico de la experiencialidad.}

La versión analítica o lógico-argumental de la Filosofía para Niños descansa en la idea de que el conocimiento es generado por el sujeto. La labor del filósofo consistiría en mejorar las competencias racionales de su alumno, puesto que eso llevaría a mejorar sus habilidades racionales. Incentivar las habilidades conceptuales y el pensamiento crítico y creativo redundaría en mejores decisiones y conceptos más rigurosos, esto es, una mejor aprehensión de la realidad. Esta orientación mantiene una concepción de la verdad adecuacionista, aquella que asume la coherencia entre la cosa y el esquema mental en que se articula. De este modo, hay más verdad en la medida en que exista más cercanía hay entre lo dado y el concepto forjado.

Este modelo posee como columna vertebral y punto de partida gnoseológico al ser humano, es decir, el mejor de los conocimientos no puede saltar por encima de él, de sus capacidades de aprehensión cognoscitiva.

La versión experiencial, partiendo de las reflexiones heideggerianas vistas arriba (y de las zambranianas y gadamerianas) ofrece una perspectiva alternativa: el sujeto no crea el conocimiento sino que entra en él, o si se quiere, se sumerge en la realidad para, desde dentro, explicarlo. Cuando un niño queda absorbido en una experiencia determinada no construye un saber sino que aprehende verdades (no necesariamente traducibles en conceptos, puesto que pueden ir más allá de las palabras) nuevas por estar sumido en ese nuevo contexto. Estas verdades acostumbran a superar la potencia subjetiva limitada por los aprioris kantianos, 
propia del conocimiento analítico. Al entrar en contacto con la totalidad se aprenden contenidos holísticos entre los que el concepto manifiesta limitaciones.

La experiencia de la amistad de un niño trasciende la limitación impuesta por el concepto. Cuando un niño posee un amigo de verdad y accede al significado holístico de la "amistad", no desea perderlo porque, entre otras cosas, comprende la riqueza a la que le ha llevado ese contacto. Esa riqueza no se puede encorsetar en una definición, puesto que la vida escapa a estas estructuraciones finitas. Cuando ese niño que intenta explicar qué es la amistad sabe que algo escapa; esto es debido a que la palabra conceptual depende de un espacio y un tiempo, el propio, y cuando se vive la amistad, el niño se pone en contacto con algo más que con una circunstancia subjetivista.

Lo anterior no conduce a asumir que las experiencias no se puedan comunicar; sin embargo, el mismo acto de comunicación de la "amistad" como contenido holístico ha de transformarse. La comunicación de una experiencia depende de la comunión con otros. Así, transmitir una experiencia no sólo exige explicar un concepto sino con-vivir con otros para que en esa convivencia se transmita el contenido experiencial. Este tipo de comun(icac)ión permite intuir si el otro comprende de forma correcta los conceptos usando criterios diferentes a los analíticos. La entrada en la esfera de la amistad capacita para distinguir quien se encuentra dentro de ella y quién está más cerca del foco originador.

Ahora bien, conocimiento y aprehensión van de la mano, esto es, mientras más cerca se encuentre la persona del foco originador (esto es, aquel que posea una experiencia más auténtica o más experiencias de la matriz) estará más capacitado para evaluar la calidad de la verdad del neófito. Esto quiere decir que hay más proclividad en el principiante de errar en torno a concebir lo falso como verdadero que en el estudiante aventajado y que no existe una técnica objetiva que capacite a cualquiera que no haya recorrido personalmente el camino a realizar esta distinción de modo objetivo.

La filosofía conceptual y analítica más prudente ha aceptado la debilidad para tocar lo real sin mediaciones; sin embargo, añade, es el medio más eficaz puesto que otras metodologías no permiten la transmisión. Una experiencia es demasiado volátil (o grande) para manejarse, para trasladarse a otro sujeto y, además, carece de criterios de jerarquización para evaluar qué verdades sirven más que otras. Después de lo visto, se comprende que sus críticas son válidas dentro de su propio marco disciplinar: la transmisión de experiencias (que es una totalidad demasiado amplia para conceptualizarse) no es posible si no se traduce a palabras y sin ellas no se puede comunicar. Ahora bien, el problema reside en su incapacidad para pensar desde otro marco y para traducir sus acciones, la comprensión y la transmisión, en la estructura inherente a este otro universo, a saber pasar a la comprensión experiencial y a la comunión.

La comunicación analítica traslada un contenido envasado en un instrumento caracterizado por poseer un esqueleto espacio-temporal, el concepto, de un sujeto a otro. El receptor lo coge, lo saca de su envase e intenta comprenderlo, obviamente desde su propia experiencia. He aquí la raíz de muchos malentendidos: el emisor parte de un universo, envasa el esqueleto en un medio perdiendo parte del mensaje y, para colmo, el receptor realiza el proceso 
inverso abriendo el contenido en su propio marco experiencial. Situación diferente es la de la comunión: no se pide que los sujetos se transmitan información sino que ambos caminen a un orbe común donde la fuente originaria ayuda a los dos (o más individuos) a que comprendan el significado originario. La comunión no persigue tomar de la mano al otro para traerlo a mi verdad sino animarlo a que se una a una verdad experiencial que transciende a ambos sujetos. El concepto "amistad" no se comprende porque se explica a otra persona sino porque los dos interlocutores ingresan en esa experiencia. Repitámoslo: no hay dos miradas de dos individuos entre sí sino que éstas se dirigen a un fondo común, que las ilumina con su entraña.

En suma, la comunicación muta en comunión cuando la palabra es sustituída por un diálogo profundo, íntimo y ontológico donde se es consciente de que el concepto no es suficiente (aunque tampoco inservible) para explicar las extensas frondosidades de la experiencia que la ha producido.

\section{4. conclusión. hacia una filosofía para niños experiencial.}

Esta configuración añade un nuevo esqueleto más que escapa al logicismo y conceptualismo de ciertas propuestas de Filosofía para Niños; si bien no se niega el valor de la versión analítica o lógico-argumental. De hecho, la convivencia de ambas es factible. No nos oponemos a los beneficios de un trabajo racional sino que afirmamos que esta labor puede progresar desde las circunvoluciones aquí expuestas. Fomentar las disposiciones que promueven la experiencialidad (incluso las de los diálogos racionales) e incentivar las experiencias que descubran nuevos saberes sería el eje de esta actividad. De modo conclusivo, definiríamos la Filosofía para Niños Experiencial en los siguientes términos: Proceso de generación y monitorización de ex-periencias (directas o indirectas) sobre el niño y fomento de las disposiciones precisas para que su vivencia se transforme en experiencial con el objetivo de provocar traslados ontológicos que generen nuevas comprensiones de la realidad y de sí mismo. Tales intelecciones estarán dirigidas hacia la profundización existencial (maduración ontológica y autenticidad o cercanía a la verdad ontológica) y, por ende, al crecimiento antropológico guiados por verdades que escapan a la limitación humana. Tal actividad tendrá presente el uso de gnoseologías anagógicas e intuitivas y la promoción de las disposiciones precisas para desarrollarlas.

Desde esta definición, que explicaremos en un trabajo posterior, se entiende que la labor y formación del especialista en esta área es mucho más dinámica que la de quien se entrene, exclusivamente, en habilidades racionales. Esto no quiere decir que éstas hayan de ser abandonadas, pues, como hemos señalado, son los pilares de muchas experiencias. Ahora bien, no han de olvidar desarrollar capacidades creativas y habilidades intuitivas en el facilitador de la Filosofía para Niños, para que sea capaz de ver la base del obstáculo de un alumno y las experiencias que le ayuden a superarlo. Estas experiencias serán los nudos gordianos de un saber experiencial que lo transformará en otro sujeto, una persona donde no es preciso que desaparezcan las causas del problema, puesto que éste puede desaparecer porque se disuelve en la vida de la persona. La disolución es congruente con el cambio de marcos. La entrada en un nuevo 
universo provoca que los problemas del orbe anterior no se perciban como tales en el nuevo. La ansiedad de un niño que entra por vez primera en una clase se reduce después de la experiencia de hacer nuevos amigos. Aunque la circunstancia se mantiene, la entrada en un nuevo cosmos motivado por la experiencia provoca una disolución de su conflicto inicial: asistir a clases. Pero esto es otro tema.

Comenzamos esta investigación con las dos tendencias fundamentales que Franca D'Agostini descubría en la contemporaneidad. Aseverábamos que una de ellas se había infiltrado de modo hegemónico en la práctica de la Filosofía para Niños. Es tiempo de modificar esta tesitura si es que queremos ser consecuentes con la historia que nos precede. Quedar al albur de una única modalidad es coherente con aquel que se convierte en un técnico de la profesión, pero esta actitud no es consecuente con la misión de la filosofía: la mirada crítica y la apertura de nuevos campos de visión no sólo para los niños y jóvenes sino para el agente de esta profesión. Al fin y al cabo, afincarse acomodaticiamente en la analítica, ¿no convierte la disciplina en un discipulado y limita sus potencialidades epistemológicas y ontológicas?

\section{referencias}

APPEL, Karl-Otto. La transformación de la filosofía. Tomo I. Madrid: Taurus, 1985a.

. La transformación de la filosofía. Tomo II. El a priori de la comunidad de comunicación.

Madrid: Taurus, $1985 \mathrm{~b}$.

ANTÓN PACHECO, José Antonio. El ser y los símbolos. Madrid: Mandala, 2010.

BARRIENTOS-RASTROJO, José. Abrir preguntas esenciales como quehacer del maestro. De la quiebra de la pedagogía bancaria de Freire a la pregunta esencial gadameriana y al saber de la experiencia zambraniana. Diálogo filosófico, 2013(86), pp. 325-352.

. An Experience workshop with groups. Theory and practice. In WEISS, Michael (ed). The Socratic handbook. Zürich: Lit Verlag, 2015a, pp. 375-383.

A recuperação do ser pela palavra como meio para a (re)conciliação entre a Filosofia Aplicada e a Filosofia Académica. In PINTO, Joaquim. Bernard Lonergam e a Filosofia Aplicada. Lisboa: Universidad Católica Portuguesa, 2014a, pp. 174-197.

. El rostro de la experiencia desde la marea orteguiana y zambraniana. In Endoxa, 2010, número 25, pp. 279-314.

. La fisiología del saber de la experiencia y los frutos de su posesión. In Themata, número 44, 2011a, pp. 79-96

. L'orientamento esperienziale nella Filosofia Applicata como ampliamento della tendenza logico-argomentativa. In Rivista Italiana di Counseling Filosofico, $\mathrm{n}^{\mathrm{o}}$ 11, 2015b, pp. 9-31.

Los símbolos desfallecidos. México DF: Analogía Filosófica, 2014b.

Vectores zambranianos para una teoría de la filosofía aplicada a la persona. Sevilla: Universidad de Sevilla, 2010.

Factory, 2013

(ed.). Filosofía para niños y capacitación democrática freiriana. Madrid: Liber

BEUCHOT, Mauricio; ARENAS-DOLZ, Francisco. Hermenéutica en la encrucijada. Analogía, retórica y filosofía. Barcelona: Anthropos, 2008.

BEUCHOT, Mauricio; BARRIENTOS-RASTROJO, José. La Filosofía Aplicada desde la Hermenéutica Analógica. México DF: Torres, 2013.

COMTE-SPOVILLE, André. El amor. La soledad. Barcelona: Paidós, 2000. 
la experiencialidad como respuesta a la tendencia analítica de la filosofía para niños

D'AGOSTINI, Franca. Analíticos y continentales. Guía de la filosofía de los últimos treinta años. Madrid: Cátedra, 2000.

BRENIFIER, Oscar. Filosofar como Sócrates. Introducción a la práctica filosófica. Valencia: Diálogo, 2011,

DEWEY, John. Como pensamos. Nueva exposición de la relación entre pensamiento reflexivo y proceso educativo. Barcelona: Paidós, 2007.

ECHEVERRÍA, Eugenio. Filosofía para niños. México DF: SM, 2006.

FISHER, Robert. Cuentos para pensar. Barcelona: Obelisco, 2007.

GADAMER, Hans Georg. Arte y Verdad en la palabra. Barcelona: Paidós, 1998. Verdad y Método. Salamanca: Sígueme, 1993.

GOPNIK, Alison. El filósofo entre pañales. Relaciones sorprendentes sobre la mente de los niños y cómo se enfrentan a la vida. Madrid: Planeta, 2010.

HAYNES, Joana. Los niños como filósofos. El aprendizaje mediante la indagación y el diálogo en la escuela primaria. Barcelona: Paidós, 2004.

HEIDEGGER, Martin. Caminos del bosque. Madrid: Alianza, 2001.

JAMES, William. Pragmatismo. Un nuevo nombre para viejas formas de pensar. Madrid: Alianza, 2000.

KOHAN, Walter - WAKSMAN, Vera. Filosofía con Niños. Aportes para el trabajo en clase. Buenos Aires: Noveduc, 2000.

LEVINAS, Emmanuel. El humanismo del otro hombre. Madrid: Caparrós, 1993.

LIPMAN, Matthew. El descubrimiento de Harry. Madrid: Ediciones de la Torre, 1997. Philosophy goes to school. Philadelphia: Temple University Press, 1988.

LIPMAN, Matthew - SHARP, Ann - OSCAYAN, Francis. La filosofía en el aula. Madrid: Ediciones de la Torre, 1998.

LÓPEZ ARANGUREN, José Luís. La experiencia de la vida. In AA.VV. Experiencia de la vida. Madrid: Alianza, 1966.

ORTEGA Y GASSET, José. Obras completas VIII. Madrid: Alianza, 1994.

PUIG, Irene - SÁTIRO, Angélica. Jugar a pensar con cuentos. Barcelona: Octaedro/Eumo, 2000.

SÁEZ RUEDA, Luis. El conflicto entre analíticos y continentales. Barcelona: Crítica, 2002.

SÁNCHEZ ALCÓN, José Manuel. Pensamiento libre para personas con discapacidad intelectual. Madrid: Pirámide, 2011.

SÁTIRO, Angélica. Jugar a pensar con niños de 3 a 4 años. Barcelona: Octaedro, 2004.

STRAWSON, Peter Frederik. Introduction to logical theory. Londres: Routledge, 2012.

WITTGENSTEIN, Ludwig. Investigaciones filosóficas. Barcelona: Crítica, 2008.

YALOM, Irvin. Quando Nietzsche Chorou. Parede: Saída de Emergencia, 2007.

ZAMBRANO, María. Cartas de la Pièce. Valencia: Pretextos, 2002.

. Claros del bosque. Barcelona: Seix Barral, 1993.

Notas para un método. Madrid: Mondadori, 1989.

El sueño creador. Madrid: Turner, 1986.

ZUBIRI, Xavier. Inteligencia sentiente. Madrid: Tecnos, 2004.

. Sócrates y la sabiduría griega. Escorial 2, 1940, pp. 187-226.

Recibido en: 10.05 .2016

Aprobado en: 10.08.2016 